\title{
The P-A-I-N-S Typology of Health Literacy Perspectives Among Filipino Chronic Non-Malignant Pain Sufferers: A Q Methodology Study
}

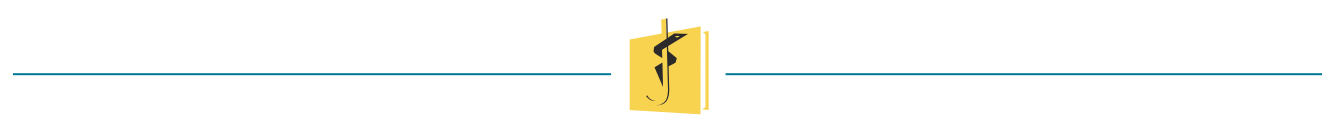

Maria Minerva P. Calimag, MD, PhD

\begin{abstract}
Introduction: Pain is an unpleasant sensory and emotional experience associated with actual or potential tissue damage, or described in terms of such damage (IASP). Acute pain is a positive experience that performs a survival function. However, when the pain becomes chronic, these first accounts are generally found wanting and are often replaced by more biomedical accounts of illness and cure. As a culturally-invested construct and a private sensation that cannot be reduced by objectification, this paper proposes to segment the health literacy perspectives in the eyes of the Filipino chronic non-malignant pain sufferer through the lens of the social constructionist theory. The intent is to explore the extent to which such domains require a rethinking of the healthcare professionals' approach to the management of Filipino patients with chronic pain.
\end{abstract}

Methodology: Q-methodology is the primary design used in this study. It combines the objectivity of quantitative approach with the essence of human experiences as explored in qualitative studies. The participants (P-sample) were 30 subjects gathered by a purposive sample of participants with chronic

Maria Minerva P. Calimag

mpcalimag@ust.edu.ph

Faculty of Medicine and Surgery, University of Santo

Tomas, Manila, Philippines pain. They were asked to arrange 33 statements (Q-sample), derived from literature, in the Q-sort table based on their degree of agreement, which was then further explicated in the post-sort interviews. The results were then subjected to by-person factor analysis with Varimax rotation using the $P Q$ method version 2.11.

Results and Discussion: This paper evolves the P-A-I-N-S Typology of Health Literacy Perspectives Among Filipino Chronic Pain Sufferers. The PASSIVE perspective resonates with mere acceptance and thoughts of self-efficacy but very minimal self-management behavior. The ACTIVE perspective reflects moderate self-efficacy and self-management skills moderated by acceptance of their chronic pain condition. The INFORMED perspective shows a tendency towards self-management behaviors to control their pain through the use of the internet. The NEGATIVE perspective (Profile B) shows a highly catastrophizing attitude towards their pain with minimal acceptance and self-efficacy skills. Their consensus statements revealed a SPIRITUAL stance that allows them to take on and bear their pains silently, yet allowing them to carry on with their activities of daily living, thus living through their chronic pain experience while fostering a balance between hope and resignation.

Conclusion: This typology of Filipino chronic pain patients according to specific health literacy domains of catastrophizing, acceptance, self-efficacy, and 
self-management contributes to knowledge about the continuum of care that should be afforded by these patients. A patient's type should be considered as a dynamic starting point, so interventions can be instituted to move them from the catastrophizing to the self-management end of the spectrum.

Keywords: Filipino, Chronic Non-malignant Pain, Health Literacy, Q methodology

\section{INTRODUCTION}

Pain is an unpleasant sensory and emotional experience associated with actual or potential tissue damage, or described in terms of such damage (IASP). Acute pain is a positive experience that performs a survival function to promote behavior aimed at avoidance from actual or potential harm. [1] However, pain as described also depicts two negative characteristics: first, that of an interruptive and unpleasant experience [2,3] and second, that of progression to chronification when it persists long after its survival value is spent. Aldrich \& Eccleston [4] derived a social constructionist analysis of acute pain (ie, short-lived) such as pain as malfunction; pain as self-growth; pain as spiritual growth; pain as an alien invasion; pain as coping and control; pain as abuse; pain as homeostatic mechanism; and pain as power. However, when the pain becomes chronic (ie, long-lasting), these first accounts are generally found wanting and are often replaced by more biomedical accounts of illness and cure. $[5,6]$ When a person has pain that is chronic, the search for cure and meaning is intensified and can come to dominate. $[7,8]$. Sooner or later the person with a chronic condition will be confronted with a discourse of adaptation and will be asked to contemplate acceptance of a life with pain.[9] Although the idea of living a full life despite chronic pain is common in therapeutic domains, it is counter-intuitive, especially for the chronic pain sufferers who are struggling to make sense of their experience.[10]

Health literacy $(\mathrm{HL})$ is defined "as the cognitive and social skills which determine the motivation and ability of individuals to gain access to, understand, and use information in ways which promote and maintain good health. "[ 11 1]

The international discussion over health literacy often leans on the levels of health literacy created by
Don Nutbeam [12]: basic/functional health literacy, communicative/interactive health literacy, and critical health literacy.[13-15] The lowest level of health literacy means that people know about health risks and health services. [16,17]

The goal of communicative health literacy is to provide an individual with the ability to function independently, with increased motivation and self-confidence. The action aims at benefitting the individual human being. The societal benefits come from the influence on social norms and increased group activity. $[16,18]$

Stewart, et al. [19] have suggested that health literacy could be expanded to cover also social, cultural, and environmental dimensions. Critical health literacy aims at personal and communal empowerment. It strengthens people's persistence in times of facing social and economic trouble. People with critical health literacy can change general and organizational practices related to health and communicate with leaders and politicians to realize changes they consider important. Health literacy that is acquired early in life affects health positively during the whole lifespan.[20]

Brey, et al. [21] defined health literacy as the ability to search, interpret, and understand basic information about health and use the information to promote health. They divided individuals according to their information-seeking approaches to health literacy into four types: the critical thinker who studies the health problem and creates a solution; the responsible citizen who values his responsibility to maintain the community healthy, safe, and free from fear; the life-long learner who recognizes the need to use information about health during his or her whole life; and the efficient communicator who effectively expresses and shares his beliefs, ideas, and information about health to others.

The IMB model [20] recognizes three constructsinformation, motivation, and behavioral skillsneeded to engage in given health behavior, as specific individual determinants of behavior and behavioral change.[21]

Pain is a culturally invested construct and a private sensation that cannot be reduced by objectification. This paper proposes to segment the health literacy perspectives in the eyes of the Filipino chronic non-malignant pain sufferer through the lens of the social constructionism theory $[22,23]$ and the IMB model.[20] The intent is to explore the extent 


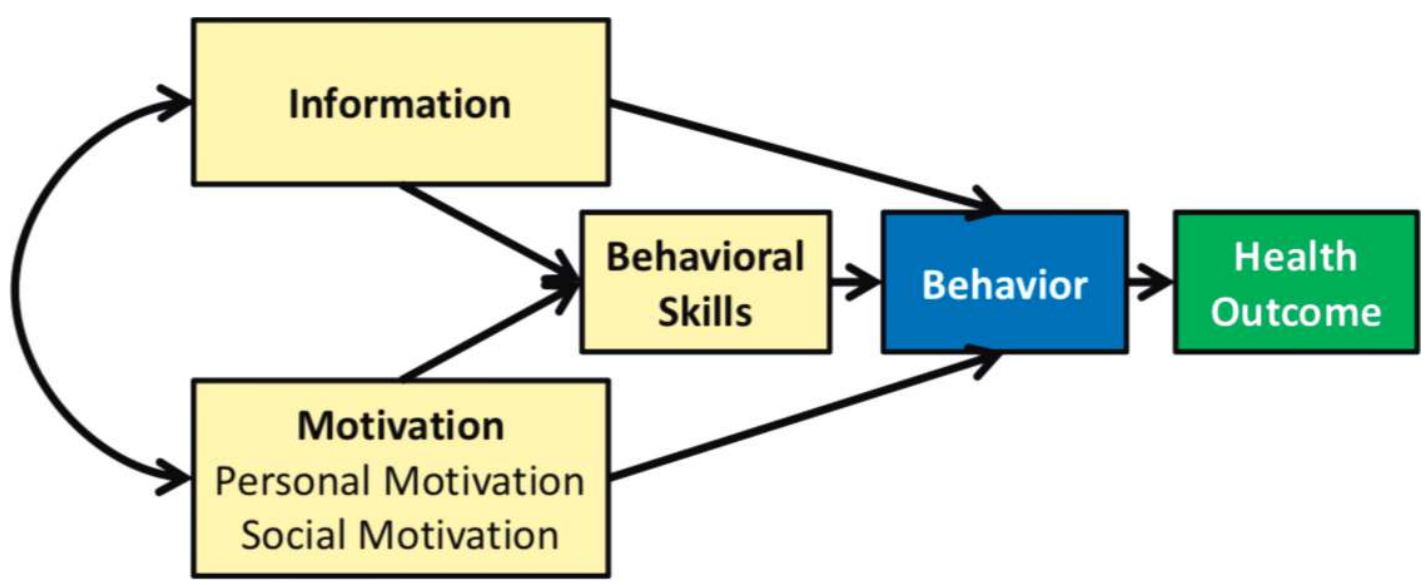

Figure 1. The Information-Motivation-Behavior Model by Fisher and Fisher, 1992

to which such domains require a rethinking of the healthcare professionals' approach to the management of Filipino patients with chronic pain.

\section{METHODOLOGY}

\section{Research Design}

The $Q$ methodology is an approach to understanding subjectivity that combines qualitative and quantitative techniques.[26] Originally developed in the 1930s, it allows for a systematic investigation into the viewpoints or perspectives of the participants in the study.[27] $Q$ is a semi-qualitative methodology to identify typologies of perspectives. It is appropriate to address questions concerning diverse viewpoints, plurality of discourses, or participation processes across disciplines. The perspectives are interpreted based on the rankings of a set of statements. These rankings are analyzed using multivariate data reduction techniques in order to find similarities between respondents.

\section{Participants}

A purposive sample of participants was assembled with the following inclusion/exclusion criteria: chronic pain of at least 3 months duration, age between 18 and 65 years, and no current malignant disease or co-morbidity. Written informed consent was obtained after the researcher oriented the participants regarding the objectives, course, and significance of the study. They were also oriented that their participation is voluntary and that they can withdraw from the study at any time they wish. Participants were assured that confidentiality will be adhered to at all times and the results of the study will only
Table 1. Patient Demographics

\begin{tabular}{lc}
\hline Variable & \\
\hline Sex & $12(40 \%)$ \\
$\quad$ Male & $18(60 \%)$ \\
$\quad$ Female & $53.8 \pm 15.5$ \\
Age (years \pm SD) & \\
Marital Status & 3 \\
$\quad$ Single & 24 \\
$\quad$ Married/living together & 3 \\
$\quad$ Separated/Widowed/Divorced & $14.6 \pm 2.0$ \\
Education (years \pm SD) & $3.0 \pm 1.8$ \\
Occupation & (scale \pm SD) \\
Illness Duration (years \pm SD) & $7.0 \pm 5.2$ \\
\hline
\end{tabular}

a On a scale ranging from 1 (housewife) to 6 (teacher)

be reported in the aggregate. A robotfoto [28] was used to depict the demographic profile of the participants. Table 1 shows the demographic and other characteristics of the participants.

\section{Research Instruments}

Three stages in data collection were undertaken for this Q-methodology study namely: the identification and sorting of statements (Q-sort), data analysis (Q-analysis), and interpretation.[29,30] A robotfoto [28] was used to depict the demographic profile of the participants.

Cultural analysis is necessary at the very first stage of $Q$ methodology. This involves knowing the culture for talk about chronic pain to create a sortable set of statements. [31] Previous studies on chronic pain by the author [32] and other pain researchers and clinicians [33] served as the basis for some of the statements in the $\mathrm{Q}$-sort. 
Table $2 a$ lists the major themes that represented the final $Q$-set. The statements used as the $Q$-sample are clustered around four conceptual frames. Studies were explored for statements to clarify specific domains related to chronic pain such as catastrophizing, acceptance, SE, and self-management. Each of the themes comprised a minimum of eight statements.

Table 2b. depicts the List of Statements or the Q-sample.

Pain catastrophizing is defined as "overapprais$\mathrm{al}^{\prime \prime}$ consisting of a set of maladaptive beliefs of the

Table 2a. Major Themes represented in the Final Q-set

\begin{tabular}{ll}
$\begin{array}{l}\text { Health Literacy in } \\
\text { Chronic Pain Domains }\end{array}$ & Statements \\
\hline Catastrophizing & $1,6,7,12,18,23,29,33$ \\
Acceptance & $2,8,11,13,19,24,30,31$ \\
Self-Efficacy & $3,4,14,15,21,22,25,26,32$ \\
Self-Management & $5,9,10,16,17,20,27,28$ \\
\hline
\end{tabular}

negative aspects/consequences toward an actual or anticipated pain experience. It is a cognitive process whereby a person exhibits an exaggerated notion of negativity assuming the worst outcomes and interpreting even minor problems as major calamities. Catastrophizing has been found to be instrumental in exacerbating the chronic pain experience. In patients with chronic pain, catastrophizing is a significant determinant of self-rated pain intensity and disability.

Acceptance of chronic pain is typically centered on the concepts of activity engagement (the pursuit of life activities regardless of pain) and pain willingness (recognition that avoidance and control are often unworkable methods of adapting to chronic pain).[34,35] Authors further aver that acceptance of pain can be relevant because greater acceptance of and consequently less time and energy spent struggling and avoiding, pain may free up behavior to allow for the pursuit of a better quality of life. $[34,36]$

Table 2b. List of Statements (Q-Sample)

1- I worry all the time about whether the pain will end. (psychological distress)

2-I have accepted pain as a punishment for the things I have done wrong (pain willingness)

3- I am a whole person again I will fight this pain (controllability)

4- I am putting back pain where it belongs so I can move on

5-I read about my chronic pain condition in the internet (partnership in care with proactive information-seeking)

6- No one helps me with what I feel (life control)

7- Pain medication cannot really control my pain (focus on pain intensity)

8- This pain experience is hard to go through and I really need help (activity engagement)

9-I have autonomy over the management of my pain (self-advocacy)

10-I have a great deal of control over the management of my pain (self-advocacy)

11- Pain is permanent but I have not learned to accept it (pain willingness)

12- I will not be able to live my life as well as people who have no pain (life control)

13- I am not trying to run from the experience anymore (activity engagement)

14- I have some control over my pain (controllability)

15- Dealing with my pain takes priority

16-I only take my medications when the pain becomes bothersome (non-adherence to medication)

17- High fees prevent me from seeking consultation even when my pain is unbearable (communication with healthcare provider)

18- I do not go out and socialise anymore (interference with ADL)

19- I do not get sad or get angry because I lift up everything to God (pain willingness)

20-I look after my diet and refrain from eating food that makes my pain worse (self-care)

21- I will give up ways to control the pain that are not productive

22- I have to learn how to manage the pain myself

23- I cannot stop thinking about how much it hurts (psychological distress)

24- I engage in usual daily activities regardless of the pain (activity engagement)

25- My spiritual direction has allowed me to bear the pain silently

26- I am confident about my ability to deal with my pain

27-I ask my physician a lot of questions about my chronic pain (communication with healthcare provider)

28- Always adhering to the medication regimen is important for me (medication adherence)

29- It is awful and I feel that pain overwhelms me (focus on pain intensity)

30-I understand that pain does not inevitably mean disability (pain willingness)

31- I am able to carry on with my life activities even with the pain (activity engagement)

32- I do not allow pain to interfere with my daily activities

33- I will not be able to live my life as well as people who have no pain (interference with ADL) 


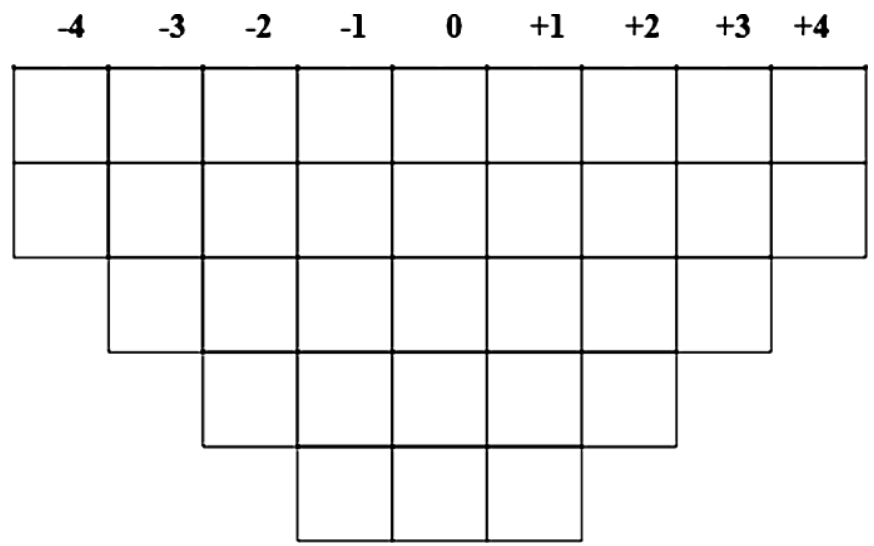

Figure 2. The Q-Sort Table

Self-efficacy (SE) is a recurring factor within the patient factors in the HL model.[37] SE is defined by Bandura as. "confidence that one can successfully execute a course action to produce a desired outcome in a given situation and contended that SE determines how much effort and persistence people exhibit in the face of obstacles or aversive experiences".[38] Thus, for people with chronic pain, SE not only includes the expectation that a person could perform a particular behavior or task but also their confidence in being able to perform a task despite the pain. La Touche, et al. [39] found that among chronic low back pain patients the high SE group had less pain in the temporal summation lifting task, a greater range of motion, and greater functional range, in addition to a lower influence of psychological factors.

Many health literacy interventions have a limited focus on functional/cognitive skills. In psychosocial models, the capacity to act however is seen as a major driver of behavioral change. This aspect is often lacking in health literacy concepts. While SE involves thought processes, self-management refers to strategizing behaviors that include: communication with caregivers, partnership in care, self-care, self-advocacy, and medication adherence.[40]

\section{Data Collection}

Each statement from the Q-set was printed on $5^{\prime \prime} \mathrm{x}$ 8" index cards (Q sort pattern: -4 (2 cards), -3 (3 cards), -2 (4 cards), - 1 (5 cards), 0 (5 cards), + 1 (5 cards), +2 (4 cards), +3 (3 cards), +4 (2 cards)). The participants, otherwise known as the P-set $(5,8)$ were asked to categorize the statements into three piles: agree, disagree, and neutral. Next, they were instructed to place the statements on the Q-sort table (Figure 2) a 9-point Likert scale.
The participants were first asked to divide the 33 questions into two parts: the "agree" and "disagree" statements. The participants were then instructed to place the statement they most agree with on the rightmost column, then alternately to place the statement they most disagree with on the leftmost column in the Q-sort table. This they do alternately until all the boxes are filled up. The neutral pile was ranked in the remaining slots in the middle. There were limited numbers of statements that could be assigned to each score. Finally, the participants were asked to justify and elaborate on the placement of statements on the Q-sort table.

\section{Q Analysis}

After the Q-sorts had been obtained and completed, they were subjected to the by-person factor analysis (centroid factor extraction) and then rotated with the Varimax method using the $P Q$ method software version 2.11.(41-43) This was done to limit the number of resultant ways the statements were sorted. A composite sort was computed for each factor representing how a participant with a $100 \%$ loading on that factor would have ordered the 33 statements.

The factors were then interpreted and illustrated as profiles using the defining statements (those with factor score of $-4,-3,+3$, and +4 in the composite sort which were determined as the extreme ends of the Q-sort table [statements placed under column no. 9 were scored as +4 and those placed under column no. 1 were scored as -4]). The distinctive statements (those with statistically significant different factor scores as compared to all other factors; $\mathrm{p}<0.05$ ) and the anchors and phenomenal referents were then used to determine the chief characteristics of each factor profile.[44] The principal themes 
Table 3. Defining Variable of the Various Factors loaded.

\begin{tabular}{lcccc}
\hline & factor $\mathbf{1}$ & factor $\mathbf{2}$ & factor $\mathbf{3}$ & factor $\mathbf{4}$ \\
\hline No. of Defining Variables & 12 & 13 & 2 & 3 \\
Avg. Rel. Coef. & 0.8 & 0.8 & 0.8 & 0.8 \\
Composite Reliability & 0.98 & 0.981 & 0.889 & 0.923 \\
S.E. of Factor Z-scores & 0.141 & 0.138 & 0.333 & 0.277 \\
\hline
\end{tabular}

S.E. - standard error

Table 4. Distinguishing Statements for Factor 1 (Profile A)

\begin{tabular}{|c|c|c|c|c|}
\hline \multicolumn{5}{|c|}{ Factor 1 (Profile A) } \\
\hline Threshold & Z Scr. & Q Sort Value & State. No. & Statement \\
\hline$P<0.0001$ & -1.58 & -3 & 12 & $\begin{array}{l}\text { I will not be able to live my life as well as people who have } \\
\text { no pain (life control) }\end{array}$ \\
\hline$P<0.0005$ & -0.92 & -2 & 2 & $\begin{array}{l}\text { I have accepted pain as a punishment for the things I have } \\
\text { done wrong (pain willingness) }\end{array}$ \\
\hline$P<0.05$ & -1.65 & -4 & 1 & $\begin{array}{l}\text { I worry all the time about whether the pain will end. (psycho- } \\
\text { logical distress) }\end{array}$ \\
\hline$P<0.05$ & -0.6 & -1 & 7 & $\begin{array}{l}\text { Pain medication cannot really control my pain (focus on pain } \\
\text { intensity) }\end{array}$ \\
\hline$P<0.05$ & -0.46 & -1 & 8 & $\begin{array}{l}\text { This pain experience is hard to go through and I really need } \\
\text { help (activity engagement) }\end{array}$ \\
\hline$P<0.05$ & 0.14 & 0 & 13 & $\begin{array}{l}\text { I am not trying to run from the experience anymore (activity } \\
\text { engagement) }\end{array}$ \\
\hline$P<0.05$ & 0.46 & 1 & 14 & I have some control over my pain (controllability) \\
\hline$P<0.05$ & 0.85 & 2 & 16 & $\begin{array}{l}\text { I only take my medications when the pain becomes bother- } \\
\text { some (non-adherence to medication) }\end{array}$ \\
\hline
\end{tabular}

were evolved using the inductive approach wherein frequently reported patterns are reflected and extensively varied raw data synthesized into brief summary formats. This approach can also develop a model/theory about the underlying structure of experiences in the gathered data.[45] The peculiarity of each profile that was generated lies in the in-depth discussion of the difference among profiles based on the four main profiles generated.

\section{RESULTS}

Table 3 shows the different factor characteristics delineating the average relative coefficient $[A R C]$, the composite reliability [CR], and the standard error of the Factor $Z$ scores.

Of the 30 participants, 12 of them were loaded to Profile $A$ ( $A R C=0.80 ; C R=0.98)$, 13 were loaded to Profile $B(A R C=0.80 ; C R=0.981), 2$ to Profile $C(A R C=0.80 ; C R=0.889)$, and 3 to Profile $D$ $(A R C=0.80 ; C R=0.923)$. Correlation between factors 1 and $3(r=0.5767), 1$ and $4(r=0.5869)$, and 3 and $4(r=0.425)$ are moderate to high while there is a low negative correlation between factors 1 and $2(r=-0.2616)$ and 2 and $3(r=-0.1375)$. The factor matrix indicating the defining sort for the different statements were classified according to profiles. For the description of each profile, the statements from the Q-sample as depicted in Tables 4-7 (figure in brackets), highlighting on the characteristic statements and the transcripts from the initial and post-sort interviews (enclosed in quotation marks) were used. The group had five consensus statements.

\section{Factor 1 (Profile A) (Table 4)}

The perspectives of Profile A participants are clustered about not worrying whether the pain will end, but believing in their ability to live life as well as people who have no pain. They negate the idea of pain as a punishment for previous wrongdoings. They have neutral perspectives about running away from the pain experience; and agree that they have 
some control over their pain. They rely on pain medications to control pain but take their medications only when the pain becomes bothersome.

\section{Factor 2 (Profile B) (Table 5)}

The participants' perspectives in Profile B centered mostly on the catastrophizing thought processes of not being able to live life as well as other people who are pain-free, worrying all the time about whether the pain will end and about how disabling the pain has become. Generally adherent to their pain medications, they nevertheless think that their pain medications cannot really control their pain. They prefer to seclude themselves and refrain from socializing, thinking that no one can help them with how they feel. They negate self-management skills related to open communication with their physicians and self-advocacy such as maintaining a healthy diet, particularly in refraining from eating food that may exacerbate their pain conditions.

\section{Factor 3 (Profile C) (Table 6)}

The participants' perspectives clustered in Profile C engage in proactive information-seeking through the Internet regarding their pain condition. They have neutral to negative perspectives regarding activity engagement when in pain, although they strongly negate catastrophizing thoughts.

\section{Factor 4 (Profile D) (Table 7)}

The perspectives of Profile D participants are clustered and centered around accepting that pain is a punishment for previous wrongdoing, although they understand that pain does not inevitably mean disability. They have neutral perspectives about socializing and exhibit unwillingness to give up unproductive ways of trying to control their pain. They have reservations about asking their physicians a lot of questions about their chronic pain condition. They strongly negate the thought that they lack help extended to them about their pain condition.

Table 5. Distinguishing Statements for Factor 2 (Profile B)

\begin{tabular}{|c|c|c|c|c|}
\hline \multicolumn{5}{|c|}{ Factor 2(Profile B) } \\
\hline Threshold & Z Scr. & Q Sort Value & State. No. & Statement \\
\hline$P<0.0001$ & -0.92 & -2 & 20 & $\begin{array}{l}\text { I look after my diet and refrain from eating food that makes my } \\
\text { pain worse (self-care) }\end{array}$ \\
\hline$P<0.0001$ & 1.32 & 3 & 1 & $\begin{array}{l}\text { I worry all the time whether the pain will end. (psychological } \\
\text { distress) }\end{array}$ \\
\hline$P<0.0001$ & 0.8 & 1 & 6 & No one helps me with what I feel (life control) \\
\hline$P<0.0001$ & 0.53 & 1 & 7 & $\begin{array}{l}\text { Pain medication cannot really control my pain (focus on pain } \\
\text { intensity) }\end{array}$ \\
\hline$P<0.0001$ & 1.79 & 4 & 12 & $\begin{array}{l}\text { I will not be able to live my life as well as people who have no } \\
\text { pain (life control) }\end{array}$ \\
\hline$P<0.0001$ & -1.46 & -3 & 16 & $\begin{array}{l}\text { I only take my medications when the pain becomes bothersome } \\
\text { (non-adherence to medication) }\end{array}$ \\
\hline$P<0.0001$ & 0.46 & 1 & 29 & $\begin{array}{l}\text { It is awful and I feel that pain overwhelms me (focus on pain } \\
\text { intensity) }\end{array}$ \\
\hline$P<0.0001$ & -0.92 & -2 & 4 & I am putting back pain where it belongs so I can move on \\
\hline$P<0.0001$ & -1.72 & -4 & 21 & I will give up ways to control the pain that are not productive \\
\hline$P<0.0001$ & 0.92 & 2 & 23 & $\begin{array}{l}\text { I cannot stop thinking about how much it hurts (psychological } \\
\text { distress) }\end{array}$ \\
\hline$P<0.0001$ & -1.72 & -4 & 27 & $\begin{array}{l}\text { I ask my physician a lot of questions about my chronic pain } \\
\text { (communication with healthcare provider) }\end{array}$ \\
\hline$P<0.0005$ & 0.04 & 0 & 28 & $\begin{array}{l}\text { Always adhering to the medication regimen is important for me } \\
\text { (medication adherence) }\end{array}$ \\
\hline$P<0.005$ & 0.9 & 2 & 18 & I do not go out and socialise anymore (interference with ADL) \\
\hline$P<0.05$ & 0.03 & 0 & 31 & $\begin{array}{l}\text { I am able to carry on with my life activities even with the pain } \\
\text { (activity engagement) }\end{array}$ \\
\hline
\end{tabular}


Table 6. Distinguishing Statements for Factor 3 (Profile C)

\begin{tabular}{|c|c|c|c|c|}
\hline \multicolumn{5}{|c|}{ Factor 3(Profile C) } \\
\hline Threshold & Z Scr. & Q Sort Value & State. No. & Statement \\
\hline$P<0.0001$ & 1.34 & 3 & 5 & $\begin{array}{l}\text { I read about my chronic pain condition in the internet (partner- } \\
\text { ship in care with proactive information-seeking) }\end{array}$ \\
\hline$P<0.005$ & 0 & 0 & 24 & $\begin{array}{l}\text { I engage in ususal daily activities regardless of the pain (activity } \\
\text { engagement) }\end{array}$ \\
\hline$P<0.05$ & -1.34 & -3 & 8 & $\begin{array}{l}\text { This pain experience is hard to go through and I really need } \\
\text { help (activity engagement) }\end{array}$ \\
\hline$P<0.05$ & -0.89 & -2 & 23 & $\begin{array}{l}\text { I cannot stop thinking about how much it hurts (psychological } \\
\text { distress) }\end{array}$ \\
\hline$P<0.05$ & -1.79 & -4 & 29 & $\begin{array}{l}\text { It is awful and I feel that pain overwhelms me (focus on pain } \\
\text { intensity) }\end{array}$ \\
\hline$P<0.05$ & -0.89 & -2 & 31 & $\begin{array}{l}\text { I am able to carry on with my life activities even with the pain } \\
\text { (activity engagement) }\end{array}$ \\
\hline
\end{tabular}

Table 7. Distinguishing Statements for Factor 4 (Profile D)

\begin{tabular}{|c|c|c|c|c|}
\hline Factor 4(Profile D) & & & & \\
\hline Threshold & Z Scr. & Q Sort Value & State. No. & Statement \\
\hline$P<0.0001$ & 0 & 0 & 27 & $\begin{array}{l}\text { I ask my physician a lot of questions about my chronic pain } \\
\text { (communication with healthcare provider) }\end{array}$ \\
\hline$P<0.005$ & 0 & 0 & 18 & I do not go out and socialise anymore (interference with ADL) \\
\hline$P<0.005$ & -0.45 & -1 & 21 & I will give up ways to control the pain that are not productive \\
\hline$P<0.01$ & 0.89 & 2 & 30 & $\begin{array}{l}\text { I understand that pain does not inevitably mean disability (pain } \\
\text { willingness) }\end{array}$ \\
\hline$P<0.05$ & -1.34 & 3 & 2 & $\begin{array}{l}\text { I have accepted pain as a punishment for the things I have done } \\
\text { wrong (pain willingness) }\end{array}$ \\
\hline$P<0.05$ & -1.79 & -4 & 6 & No one helps me with what I feel (life control) \\
\hline
\end{tabular}

Table 8. Consensus Statements across Typologies (Profile E)

\begin{tabular}{lcl}
\hline Consensus(Profile E) & & \\
\hline Q Sort Value & State. No. & Statement \\
\hline-3 & 26 & I am confident about my ability to deal with my pain \\
-1 & 22 & I have to learn to manage the pain myself \\
-1 & 10 & Pain is permanent but I have not learned to accept it (pain willingness) \\
1 to 3 & 25 & My spiritual direction has allowed me to bear the pain silently \\
4 & 32 & I do not allow pain to interfere with my daily activities \\
\hline
\end{tabular}

Consensus statements revealed a spiritual stance that allows them to bear their pain silently. They signify the willingness to accept the permanence of pain. They also agreed that regardless of the profile they can rise above their condition and not allow pain to interfere with their daily activities and even while they are not confident about their ability to deal with and manage their pain.

Figure 3 is a radar chart that visually represents the distinguishing statements from the four profiles.
A radar chart is a graphical method of displaying multivariate data in the form of a two-dimensional chart of three or more quantitative variables represented on axes starting from the same point. The zones moving clockwise represent the catastrophizing zone (CZ) on the right upper half followed by the acceptance zone (AC), the self-efficacy zone (SE), and lastly by the self-management zone (SM). Consensus statements are common to all profiles. 


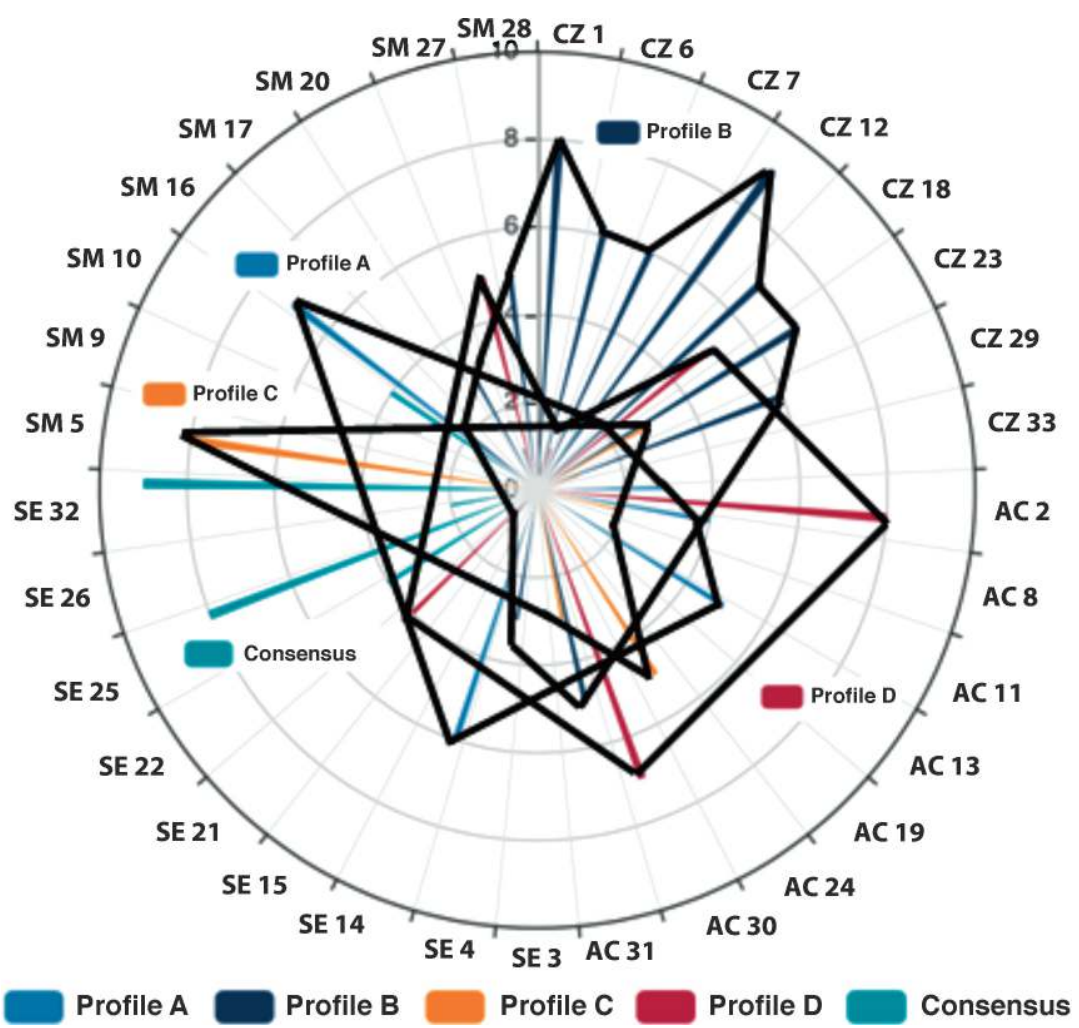

Figure 3. Radar Chart of the four (4) Typologies of Health Literacy Perspectives among Filipino Chronic Non-malignant Pain Sufferers

\section{DISCUSSION}

Health literacy is regarded as an important prereqvisite in order to take up a pro-active role with respect to one's health and lifestyle, and to be able to perform as an active partner in encounters with healthcare professionals and institutions. This is especially relevant for people with one or more chronic conditions, who have more frequent interactions with healthcare professionals and are supposed to be active in self-management of their disease.

Many health literacy interventions have a limited focus on functional/cognitive skills. In psychosocial models, the capacity to act however is seen as a major driver of behavioral change. This aspect is often lacking in health literacy concepts. There is a need to focus on skills and abilities that are mediated by environmental demands and situational complexities-the context in which health literacy is developed and applied.

In the context of chronic pain, both cognitive and non-cognitive aspects of health literacy are important, and they enhance each other. The capacity to act is especially important for the extent to which people feel able to self-manage.
In this paper is evolved the P-A-I-N-S Typology of Health Literacy Perspectives among Filipino Chronic Pain Sufferers.

The PASSIVE perspective typified by Profile $D$ resonates with mere acceptance and thoughts of SE, but very minimal self-management behavior. People with limited $\mathrm{HL}$ tend to be passive in the medical encounter and less effective self-managers, as was described [45] in the conceptual framework of HL and the patient-provider relationship. Interventions with more focus on the training of patients and tailored to the individual's HL and activation level will likely lead to more effective behavior regarding health and healthcare.

The ACTIVE perspective typified by Profile A shows moderate SE and self-management skills moderated by acceptance of their chronic pain condition. Social-cognition models acknowledge that motivation alone is not the sole predictor of taking a health action. Concepts such as SE and practical barriers such as the financial costs associated with action influence the translation of intentions into action, that is, the action phase. $[46,47]$ Individuals must accept the chronic nature of their pain before they are ready to listen to self-management 
teaching. Statement 16 (I only take my medications when the pain becomes bothersome (non-adherence to medication) is typical of Filipinos. In her article "Filipino attitude towards pain medication," Galanti [48] mentioned the fact that "Filipino nurses tend to undermedicate their patients... because stoicism is highly valued and, for Catholic Filipinos, suffering is an opportunity to demonstrate virtue". This resonates with the group's consensus in Statement 25 (My spiritual direction has allowed me to bear the pain silently).

The INFORMED perspective in Profile $C$ shows a tendency towards self-management behaviors to control their pain through the use of the Internet. With more people accessing the Internet to help themselves in managing their conditions, comes the impetus to make sure that pain management advocates to promote lay education by simplifying the jargon for online teaching about self-management of pain. Ayers, et al. [49] found a direct correlation between change in health behavior among patients with chronic illness and the increased frequency in Internet use as a source of health information. The current trends in seniors' patient care reveal that practitioners have moved away from a provider-dependent [paternalistic] model to one where patients are involved in various aspects of health decision-making; however, these seniors most of whom suffer from debilitating chronic pain need help in seeking health information in this digitized world. [50] According to Costello, [51] at least five types of medical advice were present on social platforms: over-the-counter remedies, prescription drugs, illicit substances, seeing a different healthcare provider, and lifestyle changes.

The NEGATIVE perspective (Profile B) shows a highly catastrophizing attitude towards their pain with minimal acceptance and SE skills. Chronic pain viewed through the psychosocial lens is a demoralizing state that confronts individuals not only with the distress created by the symptoms but also with many other ongoing difficulties that comprise all aspects of their lives. Collectively, pain catastrophizing is characterized by the tendency to magnify the threat value of pain stimulus and to feel helpless in the context of pain, and by a relative inability to inhibit pain-related thoughts in anticipation of, during or following a painful encounter. Jensen, et al. [52] found that decreases in pain catastrophizing were associated with 6-and 12-month improvements in disability, pain intensity, and depression in a heterogeneous sample of pain patients. Furrer, et al. [53] found that pain catastrophizing significantly mediated the effect of subjective well-being on pain intensity and pain interference, but not on depression. As an emotional experience, resilience is necessary because chronic pain can deplete emotional reserves [54] and promoting positive emotion in this context is necessary to overcome the negative. [55]

Their consensus statements revealed a SPIRITUAL stance that allows them to take on and bear their pains silently, yet allowing them to carry on with their activities of daily living thus living through their chronic pain experience while fostering a balance between hope and resignation. There is growing recognition that persistent pain is a complex and multidimensional experience stemming from the interrelations among biological, psychological, social, and spiritual factors. Patients with pain use a number of cognitive and behavioral strategies to cope with their pain, including religious/spiritual factors, such as prayers, and seeking spiritual support to manage their pain. Tan [56] opines about how "Filipino pathos and algos are shaped by two important forces: religion and feudalism." Narratives about how Filipinos cope with pain are profuse with the concept of redemptive pain, however, Statement 2 (I have accepted pain as a punishment for the things I have done wrong) in our concourse did not achieve consensus across all participants although it ranked high (Rank 4) in the PASSIVE (Profile D) type.

Studies have shown that a strong illness identity, passive coping, belief in a long illness duration, belief in more severe consequences as typified in the NEGATIVE (Profile B) and the PASSIVE (Profile D) perspectives were associated with worse outcome on disease-specific measures of functioning and on the general role and social functioning. Coping by seeking social support and beliefs in controllability/curability of the disease typified in the ACTIVE (Profile A) and the INFORMED (Profile C) perspectives were significantly related to better functioning. [57-59]

Given the chronic nature of their pain and the realities of the health care system, there is no doubt that many of these patients will be required to self-manage many aspects of their own care. The ability to measure various types of self-management behaviors among patients with chronic pain is an important first step towards understanding the scope and nature of their current involvement in their own care and treat- 
ment. Once such an assessment is accomplished, the next logical step is to conceive and design interventions directed towards improving the self-management skills of chronic pain patients. SE is a mediator of self-management and it has been definitely shown that SE can be enhanced through programs that include training, support, encouragement, positive personal experiences, and modeling. Fostering self-management by supporting SE will have longterm benefits for individuals with chronic pain.

All public health efforts to improve chronic pain outcomes should include educational strategies for both patients and health care providers that target the promotion of adherence. Regular adherence to pain therapy is dependent on the patient's acceptance that their pain is a chronic disease requiring treatment. Patients must also feel that the prescribed therapy is effective in achieving the desired treatment goals and is safe for long-term use. The beliefs that patients hold about their pain and the therapy prescribed for it are closely associated with the likelihood of adherence. When patients do not perceive that their pain is chronic or that it requires treatment, especially of the underlying disease, adherence with therapy is generally episodic. HL in chronic pain, therefore, requires more than just the usual functional, communicative, and critical dimensions but should include health information literacy and medication literacy.

This typology of Filipino chronic pain patients according to specific $\mathrm{HL}$ domains of catastrophizing, acceptance, $\mathrm{SE}$, and self-management contributes to knowledge about the continuum of care that should be afforded by these patients. The intent is not to stereotype but to generalize. According to Galanti [48], "to stereotype is to reach an ending point whereby no effort is made to ascertain whether it is appropriate to apply it to the person in question, a generalization, on the other hand, serves as a starting point...knowledge of cultural customs can help avoid misunderstanding and enable practitioners to provide better care".[60] Therefore, a patient's type in the P-A-I-N-S Health Literacy Typology should be considered as dynamic and not static, so interventions can be instituted to move them from the catastrophizing to self-management end of the spectrum. 


\section{REFERENCES}

1. Melzack R, Wall PD, Ty TC. Acute pain in an emergency clinic: latency of onset and descriptor patterns related to different injuries. Pain. 1982 Sep 1;14(1):33-43.

2. Eccleston C, Crombez G. Pain demands attention: A cognitive-affective model of the interruptive function of pain. Psychological Bulletin. 1999 May; 125(3):356.

3. Crombez G, Eccleston C, Baeyens F, Van Houdenhove B, Van Den Broeck A. Attention to chronic pain is dependent upon pain-related fear. Journal of Psychosomatic Research. 1999 Nov $1 ; 47(5): 403-10$.

4. Aldrich S, Eccleston C. Making sense of everyday pain. Social Science \& Medicine. 2000 Jun 1;50(1 1):1631-41.

5. Baszanger I. Deciphering chronic pain. Sociology of Health \& Illness. 1992 Jun; 14(2):181-215.

6. Garro LC. Narrative representations of chronic illness experience: cultural models of illness, mind, and body in stories concerning the temporomandibular joint (TM). Social Science \& Medicine. 1994 Mar 1;38(6):775-88.

7. Del Vecchio-Good M, Brodwin PE, Good BJ, Kleinman A, editors. Pain and resistance: The delegitimation and relegitimation of local worlds. Pain as human experience: An anthropological perspective. 1992:169-97.

8. Morris DB. The culture of pain. Univ of California Press; 1991 Sep 9.

9. Frank AU. Qualitative spatial reasoning with cardinal directions. In7. Österreichische Artificial-Intelligence-Tagung/ Seventh Austrian Conference on Artificial Intelligence 1991 (pp. 157-167). Springer, Berlin, Heidelberg.

10. Eccleston C, Amanda CD, Williams, Wendy Stainton Rogers. Patients' and professionals' understandings of the causes of chronic pain: blame, responsibility and identity protection. Social Science \& Medicine. 1997;45(5):699-709.

11. WHO. Health literacy and health behavior; 2009.

12. Nutbeam D. Health literacy as a public health goal: a challenge for contemporary health education and communication strategies into the 21 st century. Health Promotion International. 2000 Sep 1;15(3):259-67.

13. Abel ED, Litwin SE, Sweeney G. Cardiac remodeling in obesity. Physiological Reviews. 2008 Apr;88(2):389-419.

14. Kickbusch I. Influence and opportunity: reflections on the US role in global public health. Health Affairs. 2002 Nov;21(6): 131-41.

15. Peerson A, Saunders M. Health literacy revisited: what do we mean and why does it matter? Health Promotion International. 2009 Sep $1 ; 24(3): 285-96$.

16. Nutbeam D. Health literacy as a public health goal: a challenge for contemporary health education and communication strategies into the 21 st century. Health Promotion International. 2000 Sep 1;15(3):259-67.

17. Nutbeam D. The evolving concept of health literacy. Social Science \& Medicine. 2008 Dec 1;67(12):2072-8.

18. St Leger L. Schools, health literacy and public health: possibilities and challenges. Health Promotion International. 2001 Jun 1;16(2):197-205.

19. Stewart S, Riecken T, Scott T, Tanaka M, Riecken J. Expanding health literacy: Indigenous youth creating videos. Journal of Health Psychology. 2008 Mar; 13(2): 180-9.

20. Tsai HM, Cheng CY, Chang SC, Yang YM, Wang HH. Health literacy and health-promoting behaviors among multiethnic groups of women in Taiwan. Journal of Obstetric, Gynecologic \& Neonatal Nursing. 2014 Jan 1;43(1): 117-29.
21. Brey RA, Clark SE, Wantz MS. Enhancing health literacy through accessing health information, products, and services: An exercise for children and adolescents. Journal of School Health. 2007 Nov $1 ; 77(9): 640-5$.

22. Fisher JD, Fisher WA. The information-motivation-behavioral skills model. Emerging theories in health promotion practice and research: Strategies for Improving Public Health. 2002 Oct 15;1:40-70.

23. Ng SW, Norton EC, Popkin BM. Why have physical activity levels declined among Chinese adults? Findings from the 1991-2006 China Health and Nutrition Surveys. Social Science \& Medicine. 2009 Apr 1;68(7):1305-14.

24. Martin CM, Peterson C. The social construction of chronicity-a key to understanding chronic care transformations. Journal of Evaluation in Clinical Practice. 2009 Jun; 15(3):578-85.

25. Esposito J. Pain is a social construction until it hurts: living theory on my body. Qualitative Inquiry. 2014 Dec;20(10): $1179-90$.

26. Brown SR. Q methodology and qualitative research. Qualitative Health Research. 1996;6(4):561-7.

27. Watts $S$, Stenner P. Doing Q methodological research: Theory, method \& interpretation. Sage; 2012 Apr 4.

28. Kelchtermans $G$, Ballet K. The micropolitics of teacher induction: A narrative biographical study on teacher socialization. Teaching and Teacher Education. 2002;18(6):105-120.

29. McKeown B, Thomas D. Q-methodology. Newbury Medicine. 1998;5:1032-40.

30. Valenta A, Wigger U. Q-methodology: definition and application in health care informatics. Journal of the American Medical Informatics Association. 1997;4(6):501-10.

31. Stephenson GB. Plastic strain and stress during interdiffusion. Scripta Metallurgica. 1986 Apr 1;20(4):465-70.

32. Calimag MP, et al. A phenomenography of competing mindsets in coping with pain among Filipino older patients. Phil J Anes. 2012;23(1):35-43.

33. Javier F, Lu H. Prevalence and treatment of chronic pain in the Philippines. Philippine Journal of Internal Medicine, $2011 ; 49(2): 61-9$.

34. Vowles KE. What is acceptance of pain and why would anyone want it? 2016.

35. Cederberg JT, Cernvall M, Dahl J, von Essen L, Ljungman $G$. Acceptance as a mediator for change in acceptance and commitment therapy for persons with chronic pain? International Journal of Behavioral Medicine. 2016;23(1):21-29.

36. Thompson DP, Woby SR. Acceptance in chronic neck pain: associations with disability and fear avoidance beliefs. International Journal of Rehabilitation Research. 2017;40(3):220-26.

37. Paasche-Orlow MK, Wolf MS. The causal pathways linking health literacy to health outcomes. American Journal of Health Behavior. 2007 Sep-Oct;31 Suppl 1:S19-26. PubMed PMID: 17931132. Epub 2007/10/20. eng.

38. Bandura A. Efficacy towards a unifying theory of behavioral change. 1977.

39. La Touche R, Salud CSD, La Salle EU of Fisioterapia, CS, de Madrid A, La EU, de Madrid. How does self-efficacy influence pain perception, postural stability and range of motion in individuals with chronic low back pain? Pain Physician. 2019;22:E1-E13.

40. Curtin RB, Walters BA, Schatell D, Pennell P, Wise M, Klicko $K$. Self-efficacy and self-management behaviors in patients 
with chronic kidney disease. Advances in Chronic Kidney Disease. 2008;15(2):191-205.

41. Jedeloo S, van Staa A, Latour J, van Exel N. Preferences for health care and self-management among Dutch adolescents with chronic conditions: A Q-methodological investigation. International Journal of Nursing Studies. 2010;47(5):593-603.

42. Schmolck P, Atkinson J. PQ method. [cited 2012 Jun 15]. Available from: http://www.Irzmuenchen.de/*schmolck/ qmethod/.

43. Van Exel D, NJA, Rietveld P. "I can do perfectly well without a car!" An exploration of stated preferences for middle-distance travel. Transportation. 2011 ;38:383-407. doi:10.1007/s 1111 16-010-9315-8

44. Militello M, Benham MKP. "Sorting out" collective leadership: How Q-methodology can be used to evaluate leadership development. The Leadership Quarterly. 2010;21:620-32.

45. Roter DL. Health literacy and the patient-provider relationship. In: JG Schwartzberg, J VanGeest CC Wang (Eds.), Understanding health literacy: Implications for medicine and public health. 2005.

46. Bandura A. Social cognitive theory: An agentic perspective. Annual Review of Psychology. 2001;52;1-26.

47. Sheeran P, Trafimow D, Armitage CJ. Predicting behaviour from perceived behavioural control: Tests of the accuracy assumption of the theory of planned behaviour. British Journal of Social Psychology. 2003;42:393-410.

48. Galanti GA. An introduction to cultural differences. Western Journal of Medicine. 2000;172(5):335.

49. Ayers SL, Kronenfeld JJ. Chronic illness and health-seeking information on the Internet. Health. 2007;1 1 (3):327-47.

50. Voelker R. Seniors seeking health information need help crossing "digital divide". JAMA. 2005; 293(1 1):1310-12.

51. Costello KL. Quality of medical advice for chronic pain on social platforms. Proceedings of the Association for Information Science and Technology. 2019;56(1):381-5.

52. Jensen MP, Turner JA, Romano JM. Changes in beliefs, catastrophizing, and coping are associated with improvement in multidisciplinary pain treatment. J Consult Clin Psychol. 2001;69(4):655-62.

53. Furrer A, Michel G, Terrill AL, Jensen MP, Müller R. Modeling subjective well-being in individuals with chronic pain and a physical disability: the role of pain control and pain catastrophizing. Disability and Rehabilitation. 2019;41(5):498-507.

54. Rutter M. Implications of resilience concepts for scientific understanding. Annals of the New York Academy of Sciences. 2006;1094(1):1-12.

55. Richman LS, Kubzansky L, Maselko J, Kawachi I, Choo P, Baver M. Positive emotion and health: going beyond the negative. Health Psychology. 2005;24(4):422.

56. Tan M. Filipino Pain. Available from: https://opinion.inquirer.net/56715/filipino-pain.

57. Scharloo M, Kaptein AA, Weinman J, Bergman W, Vermeer BJ, Rooijmans HGM. Patients' illness perceptions and coping as predictors of functional status in psoriasis: a 1-year follow-up. British Journal of Dermatology. 2000; 142(5):899-907.

58. Foster NE, Bishop A, Thomas E, Main C, Horne R, Weinman J, Hay E. Illness perceptions of low back pain patients in primary care: what are they, do they change and are they associated with outcome? Pain. 2008; 136(1-2):177-87.

59. Foster NE, Thomas E, Bishop A, Dunn KM, Main CJ. Distinctiveness of psychological obstacles to recovery in low back pain patients in primary care. PAIN@. 2010;148(3):398-406.

60. Galanti GA. Filipino attitudes toward pain medication. A lesson in cross-cultural care. The Western Journal of Medicine. 2000;173(4):278-9.

(c) Open Access This article is licensed under a Creative Commons Attribution 4.0 International License, which permits use, sharing, adaptation, distribution and reproduction in any medium or format, as long as you give appropriate credit to the original author(s) and the source, provide a link to the Creative Commons license, and indicate if changes were made. The images or other third party material in this article are included in the article's Creative Commons license, unless indicated otherwise in a credit line to the material. If material is not included in the article's Creative Commons license and your intended use is not permitted by statutory regulation or exceeds the permitted use, you will need to obtain permission directly from the copyright holder. To view a copy of this license, visit http://creativecommons.org/licenses/by/4.0/. 